\title{
DA IMAGEM DA MULHER IMPOSTA PELA MÍDIA COMO UMA VIOLAÇÃO DOS DIREITOS HUMANOS
}

\author{
Cynthia Semíramis Machado Vianna \\ Mestre em Direito pela Pontifícia Universidade Católica de Minas Gerais. \\ Editora do site www.direitoinformatico.org. \\ e-mail: cynthia@direitoinformatico.org
}

RESUMO: O padrão de beleza feminina foi modificado radicalmente durante o século vinte, por meio da divulgação do corpo feminino pelos meios de comunicação. Essa mudança, longe de ser favorável às mulheres, mostrou-se uma violência psicológica, tendo em vista a imposição de uma estética de corpos extremamente magros, jovens e europeizados, características incompatíveis com a aparência da maioria das mulheres. A pressão para que os corpos femininos atinjam esse ideal estético promove distúrbios alimentares, dificulta a inserção social e profissional e gera uma relação conflituosa com o próprio corpo, já que nega as características físicas femininas. Também as crianças submetidas a esse processo midiático sofrem para se adequar a esse padrão, chegando a desenvolver distúrbios alimentares e a não aceitar o próprio corpo quando entram na puberdade. Para reverter este quadro, é fundamental promover a discussão sobre a imagem feminina, tirando-a da esfera do reforço de auto-estima e a transferindo para a esfera dos direitos humanos. Essa perspectiva é necessária porque a imagem feminina divulgada pela mídia é discriminatória, irreal, não contempla a diversidade da população feminina, é pouco saudável e prejudicial ao desenvolvimento adequado de crianças e adolescentes, sendo todas essas situações vedadas em inúmeros tratados de direitos humanos.

PALAVRAS-CHAVE: Imagem feminina; Mídia; Discriminação; Direitos humanos; Violência psicológica; Gênero; Feminismo. 


\section{INTRODUÇÃO}

A imagem do ser humano, no século vinte, foi transformada mediante dos meios de comunicação. A mídia divulgou e impôs um padrão de imagem que, longe de refletir a diversidade cultural, transformou alguns corpos em modelos estéticos a serem seguidos, mesmo que esses modelos violem as noções científicas do que deveria ser um corpo saudável.

Este trabalho busca analisar a questão da imagem feminina nos meios de comunicação atuais, sob a perspectiva do impacto psicológico e físico na vida de mulheres comuns, fazendo a correlação entre essa imagem e a violação de direitos humanos.

Para tanto, foi adotado o conceito de meios de comunicação como quaisquer formas de distribuição maciça de informação, o que envolve tanto a mídia impressa quanto a televisiva, além de anúncios publicitários e sites femininos na Internet.

Primeiramente, serão analisados alguns princípios e tratados de direitos humanos que podem ser aplicados à estética divulgada pela mídia. Em seguida, visando identificar quais são as violações a esses dispositivos, serão analisadas situações comuns à relação das mulheres com a imagem feminina divulgada pelos meios de comunicação.

Desta forma, será demonstrada que a estética feminina divulgada pela mídia não é apenas uma simples exposição de corpos, mas uma imposição que tem conseqüências nefastas para as mulheres, dificultando sua vida social, trazendo problemas de saúde e constituindo uma séria violação dos direitos humanos.

\section{DIREITOS HUMANOS E IMAGEM FEMININA}

O grande problema da imagem feminina exibida nos meios de comunicação está não só na idéia, muitas vezes inconsciente, de que a função primordial da mulher é embelezar o ambiente, mas principalmente na ausência de discussão sobre o quanto essa postura gera malefícios para as mulheres, impondo padrões estéticos discriminatórios e que contradizem explicitamente os estudos e tratados de direitos humanos das últimas décadas. 
O simples fato de ainda ser socialmente aceita essa percepção de "embelezamento do ambiente" já mostra o quão pouco as mulheres são valorizadas. Sob essa perspectiva, elas ainda não são reconhecidas como sujeitos de direito, com vontade própria, mas como objetos, sendo discriminadas e obrigadas a alegrar e enfeitar o mundo, atendendo aos padrões estéticos vigentes e tendo suas capacidades intelectuais tratadas como características secundárias, a serem admiradas apenas se a função estética for devidamente cumprida.

De acordo com 0 art. $1^{\circ}$ da Convenção Interamericana para Prevenir, Punir e Erradicar a Violência Contra a Mulher "Convenção de Belém do Pará" (1994), essas situações são uma violência contra a mulher, já que causam dano psicológico e, muitas vezes, físico ou sexual, devido à angústia de não corresponder aos padrões estéticos e, por isso, não serem totalmente aceitas pela sociedade.

Entre os direitos elencados por essa Convenção, no art. 6으, estão os de a mulher ser livre de todo tipo de discriminação e, mais importante, o direito de a mulher ser valorizada e educada livre de padrões estereotipados de comportamento e práticas sociais e culturais baseados em conceitos de inferioridade ou subordinação.

Para equilibrar a situação feminina, a Convenção do Pará estabeleceu como deveres do Estado, entre outras questões (como fomentar o conhecimento e a proteção dos direitos femininos e o incentivo à modificação de fatores socioculturais de discriminação), no art. 8ㅜ, "g", o incentivo dos meios de comunicação a que formulem diretrizes adequadas de divulgação, que contribuam para a erradicação da violência contra a mulher em todas as suas formas e enalteçam o respeito pela dignidade da mulher.

Outros tratados de direitos humanos também podem ser interpretados de forma a exigir um maior respeito pela imagem feminina. O Pacto dos Direitos Econômicos, Sociais e Culturais, em seu art. 11A, defende a proteção das pessoas para que não sofram com a fome (o que implica em investimento com segurança alimentar, adequada informação nutricional, e o incentivo a dietas que não obriguem as pacientes a passarem fome). O Pacto de Direitos Civis e Políticos enfatiza, no art. 26, a proibição de qualquer forma de discriminação, seja por motivo de motivo de "raça, cor, sexo, língua, religião, opinião política ou de outra natureza, origem nacional ou social, situação econômica, nascimento ou qualquer outra situação". 
No mesmo sentido, a Declaração Universal dos Direitos das Crianças, no seu princípio 10: a criança gozará proteção contra atos que possam suscitar discriminação racial, religiosa ou de qualquer outra natureza.

Lamentavelmente, as medidas tomadas para diminuir a discriminação em relação ao gênero ainda são bastante focadas na prevenção da violência doméstica e no planejamento familiar consciente. Embora sejam assuntos importantes, seu tratamento prioritário faz com que a questão midiática, nessa perspectiva, assemelhe-se a um luxo, ou a assunto praticamente inútil.

Porém, a deformação da imagem feminina deve ser tratada não só como assunto de saúde pública, por envolver o desenvolvimento mental feminino adequado, mas também como uma forma de discriminação, já que há tratamento completamente desigual sobre a estética feminina, privilegiando apenas alguns tipos físicos, e, no caso de crianças e adolescentes, criando um grande obstáculo ao seu desenvolvimento físico e mental.

Deve-se lembrar ainda que em vários países os canais de televisão são de concessão do Estado e têm utilidade pública. Sendo assim, não é possível aceitar que as imagens femininas transmitidas por eles sejam discriminatórias ou que envolvam um prejuízo na formação infantil.

Reconhecer que essa postura da mídia gera discriminação e impede as mulheres de desenvolverem suas capacidades físicas e intelectuais de forma plena é reconhecer que a imagem feminina também é protegida pelos direitos humanos, e deve ser adequadamente tratada no cotidiano de forma a se ter um equilíbrio entre a imagem feminina real e a apresentada pelos meios de comunicação.

\section{A DISPARIDADE ENTRE A MÍDIA E A REALIDADE}

Um estudo mundial patrocinado pela Unilever $^{1}$ apontou que $40 \%$ das mulheres não se sentem à vontade para se definirem como "bonitas". Apenas $2 \%$ das mulheres se definiu assim, enquanto $31 \%$ usaram o termo "natural" e $29 \%$ preferiram o termo "mediana". Essa mesma relação é válida para o grau de atração física, já que a avaliação da própria beleza e da atratividade física não foram global.

${ }^{1}$ Para os dados completos, confira: ETCOFF, Nancy, et. al. A verdade sobre a beleza: um relatório 
entendidas pelas entrevistadas como conceitos diferentes, mas interligados. O peso está acima do normal para $47 \%$ das entrevistadas, mesmo que, tecnicamente, muitas delas não tenham sobrepeso. A afirmação "quando me sinto menos bonita, sinto-me pior em geral" teve $48 \%$ de concordância. Para $68 \%$, a mídia divulga um padrão de beleza que as mulheres nunca poderão alcançar, e 47\% entendem que "somente as mulheres mais atraentes fisicamente são retratadas na cultura popular". A afirmação de que "mulheres bonitas têm maiores oportunidades na vida" obteve a concordância plena de $45 \%$ das entrevistadas.

De todos os países pesquisados, as mulheres brasileiras são as que mais consideraram a hipótese de cirurgia plástica (mais de $50 \%$ ), sendo que $7 \%$ já se submeteram a ela, constituindo o índice mais alto dentre todos os países. Por sua vez, $76 \%$ das entrevistadas gostaria que a beleza feminina fosse retratada na mídia como algo mais que atratividade física, e $75 \%$ gostaria de ver outros tipos de atratividade física na mídia, com variações de idade, forma e tamanho.

Porém, esse anseio por diversidade física na mídia não é atendido. As poucas empresas que direcionam seus produtos para mulheres normais são taxadas de oportunistas e de incentivarem mulheres "esteticamente fracassadas".2 Além do padrão das modelos altas e magras, há ainda a pressão para que sigam os padrões secundários e onipresentes na mídia: devem ser jovens, brancas, com cabelos lisos e traços europeus.

Desta forma, a imposição por um padrão estético totalmente incompatível com o corpo da maior parte das mulheres do mundo também tem por efeito destruir a imagem e a auto-estima femininas. Ao não serem atendidas quando gostariam de ver os diferentes tipos de corpos existentes no mundo, estão também tendo reforçada sua insatisfação e inadequação social. Para revertê-la, sentem-se na obrigação de se adaptar ao padrão de beleza imposto, de forma a serem aceitas socialmente.

A mídia transmite a essas mulheres que o controle sobre o próprio corpo é a única coisa que precisam obter para ter sucesso, serem profissionais, serem felizes.

2 Há vários comentários sob essa perspectiva em "Onde estão as mulheres imperfeitas?" (http://www.havesometea.net/MadTeaParty/archives/001593.html ). 
Porém, como a maior parte das mulheres pode afirmar ${ }^{3}$, elas não são felizes com seu corpo, que não corresponde àquele dos anúncios televisivos e impressos. Os rapazes que deveriam gostar delas preferem as moças que viram na televisão ou nas revistas, mesmo sabendo que as imagens foram manipuladas para ficarem perfeitas. As outras mulheres as rejeitam porque elas são tão fracas que não conseguem sequer fazer uma dieta corretamente para obter um corpo perfeito.

Em todos esses casos, o que se tem é uma violação dos direitos femininos. As mulheres são discriminadas pela incapacidade de se parecerem com as mulheres expostas nos meios de comunicação e não recebem o mesmo tratamento estético que os homens, tendo sua aparência julgada antes de seu trabalho. Além de não se reconhecerem nas imagens femininas expostas na mídia, ainda são pressionadas para se enquadrarem nos padrões de beleza, subverterem sua aparência e sua identidade étnica, e terem sua natureza negada enquanto sujeitos de direito.

\section{A RELAÇÃO ENTRE MAGREZA E BELEZA}

O padrão de beleza atual destoa completamente daquele de cinqüenta anos atrás, e está focado principalmente em corpos magros. A psicóloga estadunidense Mary Pipher ${ }^{4}$ afirma que em 1950 a "garota da água mineral White Rock media $1,60 \mathrm{~m}$ e pesava $63 \mathrm{~kg}$. Atualmente ela mede $1,75 \mathrm{~m}$ e pesa $50 \mathrm{~kg}$ ". Para os padrões atuais, Marilyn Monroe, por mais atraente que fosse, seria considerada gorda. Aos corpos magros, principalmente de atrizes e modelos, é atribuído um ideal de perfeição estética que deve ser seguido pelas mulheres normais.

Porém, os padrões de beleza estão cada vez mais esqueléticos. O índice de massa corporal (IMC) considerado saudável para mulheres ${ }^{5}$ é de 18,5 a $25 \mathrm{~kg} / \mathrm{m}^{2}$, mas muitas modelos são tão magras que esse índice está abaixo do nível normal. Como exemplo, a modelo da água White Rock de 1950 tem IMC de $24,6 \mathrm{~kg} / \mathrm{m}^{2}$, o

\footnotetext{
${ }^{3}$ Mary Pipher afirma, em O resgate de Ofélia, p.267: "quando me dirijo a grandes platéias, peço às mulheres que estejam satisfeitas com seu corpo que se apresentem depois da palestra. Quero ter conhecimento de sua experiência de sucesso. Até hoje nenhuma veio falar comigo".

${ }^{4}$ PIPHER, Mary. O resgate de Ofélia, p.266.

${ }^{5}$ World Health Organization, "Obesity and overweight".
} 
que corresponde à normalidade. Já a modelo atual tem IMC de $16,3 \mathrm{~kg} / \mathrm{m}^{2}$, indicando um quadro de desnutrição.

Mesmo fora do padrão de saúde, essas modelos continuam a ser contratadas, tornando-se a imagem de grandes empresas e sendo o modelo estético ideal de milhares de pessoas que não conseguem se parecer com elas.

Tamanha diferença entre padrão de beleza e realidade corporal não poderia deixar de gerar problemas. Distúrbios alimentares relacionados à aparência são cada vez mais comuns, e as pesquisas mais recentes, como foi visto, trazem índices alarmantes no que se refere à auto-estima e percepção da imagem das pessoas.

Por outro lado, há grandes preocupações com o crescente grau de obesidade da população mundial. ${ }^{6}$ Sedentarismo e mudança dos hábitos alimentares (com excesso de comida industrializada, farináceos sem valor nutritivo e gorduras) são apontados como causas dessa epidemia.

O paradoxo entre o modelo ideal de beleza cada vez mais magro, com pessoas reais cada vez mais obesas, é resolvido pelos meios de comunicação de uma forma simples e consumista: em todo veículo voltado para as mulheres há diversos anúncios de produtos dietéticos ou com valores calóricos reduzidos, além de matérias com dietas (muitas delas restritivas demais ou sem fundamento científico) e fórmulas milagrosas para emagrecimento.

A crítica a essa postura pode ser vista em meios de comunicação alternativos, como sites feministas e blogs espalhados na Internet. Em alguns dos blogs, há a crítica ao padrão de beleza atual e relatos que mostram a reação a esses modelos, notadamente nos países escandinavos, onde há maior mobilização das mulheres (inclusive pichando anúncios ofensivos) e ausência da exploração do corpo da mulher para vender produtos não relacionados a ele. ${ }^{7}$

Embora incipiente, essas atitudes mostram que há um descontentamento com o ideal de beleza associado à magreza e juventude. Privilegiar apenas um tipo físico e uma faixa etária quando há uma diversidade de corpos, formas e idades,

\footnotetext{
${ }^{6}$ Para maiores informações, confira o relatório da World Health Organization: "Obesity and overweight".

${ }^{7}$ A esse respeito, ver "Contra o padrão Barbie!!!" (http://www.sindromedeestocolmo.com/archives/000391.html), "Eu me amo, não posso mais viver sem mim..." (http://www.sindromedeestocolmo.com/archives/000393.html), "Ação da Sociedade Civil contra as propagandas de cerveja" (http://cxdepandora.blogspot.com/2005/03/ao-da-sociedade-civilcontra-as.html ) e "Emagrecer é preciso?" (http://direitoinformatico.org/cynthia/?p=157 ).
} 
todas belas, é introduzir na sociedade um comportamento discriminatório e ofensivo, totalmente contrário aos direitos humanos.

\section{O IMPACTO DOS PADRÕES DE BELEZA NA VIDA INFANTIL}

As crianças sofrem duplamente com o padrão de beleza imposto pela mídia: crescem com apelos comerciais para consumir produtos pouco saudáveis, mas não podem engordar, para não serem desprezadas pelos colegas de escola, pelos parentes nem, futuramente, pelos namorados e empregadores.

Pesquisa australiana recente ${ }^{8}$ chegou à conclusão de que meninas de 6 anos podem ser vítimas de anorexia. A pesquisa foi realizada com meninas de 5 a 8 anos, que relataram desejarem ser mais magras, já que essa característica lhes traria maior aceitação social.

O grande problema decorrente dessa preocupação infantil é observado com a transformação do corpo durante a puberdade. Incapazes de aceitar as mudanças em suas formas e o aumento do grau de gordura corporal, muitas meninas se entregam às dietas de emagrecimento, às vezes até dificultando ou impedindo o processo metabólico natural. O impacto em suas vidas pode variar de baixa autoestima e insatisfação duradoura com seu corpo, passando pelo desenvolvimento de distúrbios alimentares e anorexia, podendo chegar à morte.

A anorexia, que atinge em sua maioria adolescentes do sexo feminino, é uma doença caracterizada pelo medo anormal de engordar, além de técnicas de emagrecimento drásticas que deixam a paciente com $40 \mathrm{~kg}$ ou $30 \mathrm{~kg}$, podendo ainda sofrer infertilidade e desequilíbrios metabólicos que levam à morte. As técnicas incluem desde a falta de alimentação (chamada de no food) até episódios de bulimia (provocar vômitos após as refeições, "carinhosamente" chamada de mia), passando por excesso de exercícios físicos. Essas meninas não se reconhecem como doentes, chamam seu estilo de vida de ana, sabem que podem morrer por agirem assim, mas usam a Internet para se incentivarem mutuamente e trocarem técnicas de emagrecimento. Embora sejam o extremo da preocupação com o corpo feminino, não podem ser ignoradas, já que especialistas em distúrbios alimentares

\footnotetext{
${ }^{8}$ Para maiores informações, confira: MENINAS de 6 anos podem ser vítimas de anorexia, diz pesquisa; BBC Brasil.com
} 
consideram que a pressão pelo corpo feminino magro está se transformando em uma epidemia de anorexia. $^{9}$

Após sobreviver à crise da adolescência, essas meninas alimentam eternamente uma indústria de dietas, produtos de emagrecimento e revistas que exploram o mito do corpo perfeito e a necessidade de obtê-lo para ser considerada uma pessoa bem-sucedida.

As mulheres estão sendo cada vez mais levadas a experimentar seus corpos como inadequados diante das imagens veiculadas, esculpidas em salas de ginástica e de cirurgias, ou retocadas em estúdios fotográficos. Imagens freqüentemente associadas à idéia de corpos livres e liberados, de quem sabe o que quer e é dono de seu próprio nariz, corpos que são vendidos como passaporte para o sucesso e a felicidade.

É interessante observar o quanto o corpo feminino vendido como ideal é um corpo falicizado em que as marcas da feminilidade vão sendo aos poucos apagadas. De um lado, modelos cada vez mais jovens, cujas imagens são exploradas como um fetiche, correm o risco de serem deixadas de lado se seus corpos, ao final da adolescência, ganharem formas femininas exuberantes demais para permanecerem como modelos para as comuns mortais. De outro lado, um belo corpo vai sendo cada vez mais aquele que mediante um intenso trabalho físico vai ressaltando músculos, definindo barrigas, braços e pernas, tentando diminuir a camada de gordura, valorizando uma estética de contornos claramente masculinos. Para se sentirem belas as mulheres precisam lutar não só contra a balança mas também contra os contornos de seus próprios corpos. ${ }^{10}$

A representação feminina na mídia é a referência de beleza e atitude não só de adultos, mas também de crianças, que mais tarde repetirão o que viram e acharam agradável. Sob esse ponto de vista, o que se tem hoje, em termos de mídia, é o colapso de toda e qualquer forma de respeito pela mulher: o padrão de beleza é europeizado e nega corpos normais e com características especifícas (como o das latinas ou orientais, por exemplo), a imagem é mais valorizada que a inteligência ou capacidade de trabalho, o corpo nu que vende qualquer produto é mais valorizado que a mulher de carne e osso, a participação feminina é decorativa

\footnotetext{
${ }^{9}$ Para maiores detalhes, ver BALLONE, G.J., Anorexia Nervosa.
} 
ou destinada a assuntos domésticos como arrumar (ou manter) um casamento, cozinhar, decorar a casa e cuidar das crianças.

Dessa forma, o desenvolvimento feminino é prejudicado desde a infância. São discriminadas pela aparência, incentivadas a modificar seus corpos, a se preocupar exageradamente com aceitação social. Sofrem muito mais exigências físicas e sociais que os meninos da mesma idade, o que é uma violação de qualquer interpretação que se possa ter de um princípio da igualdade. Afinal, não é possível ter igualdade de gênero em um sistema que, desde a tenra idade, força as meninas a se perceberem como física e socialmente inadequadas.

Nesse processo eminentemente midiático, as meninas aprendem desde cedo que a beleza é mais importante que a inteligência e, ao se esforçarem apenas para serem bonitas, desprezam todas as outras formas de participação social, inclusive estudo e trabalho.

Contrariando expressamente o que afirma a Declaração dos Direitos das Crianças, essas meninas se tornam incapazes de aprender a cuidar adequadamente de si, exercendo suas liberdades em todos os campos do conhecimento, perdem também a oportunidades de se igualar em direitos com os homens e de exercer a cidadania plena.

\section{CONSIDERAÇÕES FINAIS}

É possível constatar que o padrão de beleza imposto pela mídia, nos dias atuais, encontra-se totalmente divorciado da realidade dos corpos femininos. Não obstante, é incentivado, mesmo que, para isso, sejam adotadas práticas que põem em risco a saúde física e mental de quem deseja obter o físico "ideal".

Chama a atenção que o problema tenha caráter universal, haja vista que são recorrentes as observações de que as mulheres, em todo o mundo, não estão satisfeitas com a sua imagem ou não se consideram bonitas. Todas elas são julgadas por sua aparência, e sofrem tanto com a auto-crítica quanto com a reação social.

No entanto, não há como não notar que há diferença na discriminação entre uma mulher européia, que está bastante próxima do padrão considerado ideal, e

\footnotetext{
${ }^{10}$ NUNES, Sílvia Alexim. De menina a mulher, impasses da feminilidade na cultura contemporânea, p.6.
} 
uma mulher cujos traços são das demais etnias mundiais e demonstram miscigenação, como é o caso das mulheres latinas, orientais, africanas e árabes.

A estas, o direito à igualdade e a vedação de tratamento discriminatório não são efetivos. Por terem um padrão estético diferente do considerado ideal, sua aparência é motivo de preocupação e ansiedade, não se sentem representadas na mídia e são pressionadas para adequar seu físico aos padrões de beleza.

A iniciativa de algumas empresas de cosméticos e organizações feministas para mostrar a perversidade dessa imposição de padrões estéticos ainda não teve repercussão suficiente a ponto de alterar a percepção feminina sobre o próprio corpo ou de obrigar a mídia a repensar sua postura. Talvez seja um problema de abordagem, pois o foco ainda está no reforço da auto-estima e não na percepção de que a conduta da mídia é uma clara violação de direitos humanos.

Assim, paralelamente a essas campanhas, seria necessário fazer também um trabalho de conscientização. Este seria voltado para o reconheciemento de que a imposição de um padrão de beleza em detrimento da diversidade estética viola os princípios da igualdade de gênero e da não-discriminação, dificultando a inclusão social feminina, além de corresponder a uma ofensa aos princípios de proteção ao desenvolvimento físico e mental das crianças e adolescentes.

Nos dias atuais, em que há um desencanto tão grande das mulheres com seu próprio corpo, transferir o problema da área da auto-estima para a de direitos humanos é uma necessidade, pois permitirá um tratamento mais audacioso do problema, e poderá garantir às futuras gerações femininas o direito de existirem e não serem discriminadas pela sua aparência, podendo desenvolver suas potencialidades e exercer sua cidadania de forma plena.

\section{BIBLIOGRAFIA}

ARCOVERDE, Denise. Contra o padrão Barbie!!! Disponível na Internet em: <http://www.sindromedeestocolmo.com/archives/000391.html > Acesso em 13 mar 2004.

ARCOVERDE, Denise. "Eu me amo... não posso mais viver sem mim..." Disponível na Internet em: <http://www.sindromedeestocolmo.com/archives/000393.html >. Acesso em 16 mar 2004.

BALLONE GJ. Anorexia Nervosa. In: PsiqWeb. Disponível na Internet em: <http://www.psiqweb.med.br/ anorexia.html >. Acesso em 10 mar 2005. 
BOURDIEU, Pierre; KÜHNER, Maria Helena. A dominação masculina. 3. ed. Rio de Janeiro: Bertrand Brasil, 2003. 158 p. ISBN 8528607054.

BRUSCHINI, Cristina; UNBEHAUM, Sandra (Orgs.). Gênero, democracia e sociedade brasileira. São Paulo: Fundação Carlos Chagas, Editora 34, 2002. 448p. ISBN: 8573262362.

CASTILHO, Daniela. Onde estão as mulheres imperfeitas?. Disponível na Internet em: <http://www.havesometea.net/MadTeaParty/archives/001593.html >. Acesso em 08 mar 2005.

CONVENÇÃO Interamericana para Prevenir, Punir e Erradicar a Violência Contra a Mulher (Convenção de Belém do Pará). Disponível na Internet em: <http://www.dhnet.org.br/ direitos/sip/oea/mulher2.htm >. Acesso em 01 fev 2005.

DECLARAÇÃO Universal dos Direitos das Crianças. Disponível na Internet em: <http://www.unicef.org/brazil/decl_dir.htm >. Acesso em 01 jun 2005.

DILLON, Susana. Educando em derechos humanos. Argentina: Payné s.a., 2001. mayo 2003. 310p.

DUBY, Georges; PERROT, Michelle. Imagens da mulher. Porto: Afrontamento, c1992. 189p. ISBN 9723602016

ETCOFF, Nancy, et. al. A verdade sobre a beleza: um relatório global. Descobertas de um estudo global sobre mulheres, beleza e bem-estar. set. 2004. 35p. Disponível na Internet em: $<$ http://www.campanhapelarealbeleza.com.br/uploadedFiles/br/dove_white_paper_final.pdf> Acesso em 18 mar 2005.

FARRELL, Amy Erdman. A Ms. Magazine e a promessa do feminismo popular. São Paulo: Barracuda, 2004. 288p. ISBN: 8598490075.

FENDRIK, Silvia. Anorexia y mimetismo: Prejuicio y terror. Trabalho apresentado no II Encontro Mundial dos Estado Gerais da Psicanálise. Rio de Janeiro, nov.2003. Disponível na Internet em: <http://www.estadosgerais.org/mundial_rj/download/4c_Fendrik_137161003_esp.pdf> Acesso em 21 mar 2005.

FLORENCIO, Juliana. Ação da Sociedade Civil contra as propagandas de cerveja. Disponível na Internet em: <http://cxdepandora.blogspot.com/2005/03/ao-da-sociedade-civil-contra-as.html>. Acesso em 11 mar 2005.

FOUCAULT, Michel. A Hermenêutica do sujeito. São Paulo: Martins Fontes, 2004. 680p. ISBN: 8533619952.

GIRARD, Françoise. Las implicaciones globales de las políticas nacionales e internacionales de los Estados Unidos sobre sexualidad. jun. 2004. 31p. Disponível na Internet em: <http://www.mailman.hs.columbia.edu/cgsh/IWGSSPWorkingPaper1Spanish.pdf>. Acesso em 18 mar 2005.

HALL, Hope. Hand-Me-Down Eating Disorders. Disponível na Internet em

<http://www.adiosbarbie.com/features/features_hopehall.html> Acesso em 18 mar 2005. 
HOUAISS, Antônio. Dicionário eletrônico Houaiss da Língua Portuguesa. v.1.0. Rio de Janeiro: Editora Objetiva, 2001. 1 CD-ROM.

KATZ, Chaim Samuel; KUPERMANN, Daniel; MOSÉ, Viviane. Beleza, feiúra e psicanálise. Rio de Janeiro: Formaçao Freudiana: Contra Capa, 2004. 158 p. ISBN 8586011835

MENINAS de 6 anos podem ser vítimas de anorexia, diz pesquisa. BBC Brasil.com. Disponível na Internet em: <http://www.bbc.co.uk/portuguese/ciencia/story/2005/03/050307_anorexiaml.shtml>. Acesso em 10 mar 2005.

MENTAL health of children and adolescents. World Health Organization, European Ministerial Conference on Mental health. Helsinki, 12-15 jan 2005. 7p. Disponível na Internet em: <http://www.euro.who.int/document/MNH/ebrief14.pdf> Acesso em 21 mar 2005.

NATIONAL Eating Disorders Association. Eating Disorders Information Index. Disponível na Internet em: < http://www.nationaleatingdisorders.org/p.asp?WebPage_ID=294> Acesso em 15 mar 2005.

NUNES, Sílvia Alexim. O corpo da mulher entre a cruz e a caldeirinha: um estudo sobre a mulher, o masoquismo e a feminilidade. Rio de Janeiro: Civilização Brasileira: 2000. 255p. ISBN: 8520005071.

NUNES, Sílvia Alexim. De menina a mulher, impasses da feminilidade na cultura contemporânea. Trabalho apresentado no II Encontro Mundial dos Estado Gerais da Psicanálise. Rio de Janeiro, nov.2003. Disponível na Internet em: <http://www.estadosgerais.org/mundial_ri/download/ 5c_Nunes_83071003_port.pdf>. Acesso em 18 nov 2004.

PACTO dos Direitos Civis e Políticos. Disponível na Internet em: <http://www.dhnet.org.br/direitos/ sip/onu/doc/pacto2.htm >. Acesso em 08 ago 2004.

PACTO dos Direitos Econômicos, Sociais e Culturais. Disponível na Internet em: <http://www.dhnet.org.br/direitos/sip/onu/doc/pacto1.htm>. Acesso em 08 ago 2004.

PERROT, Michelle. Mulheres publicas. São Paulo: Ed. UNESP, 1998. 159p. v. 21 n. 3 [May 1996] ISBN 857139220X.

PIOVESAN, Flávia. Direitos humanos e o direito constitucional internacional. São Paulo: Max Limonad, 1997.

PIPHER, Mary Bray. O resgate de Ofelia: o drama da adolescente no mundo moderno. São Paulo: Martins Fontes, 1998 444p ISBN 8533608357

ROBELL, Suzanne. A mulher escondida: a anorexia nervosa em nossa cultura. São Paulo: Summus, 1997. 141p. ISBN 853230608X (Broch.)

SPIGNESI, Angelyn. Mulheres famintas: uma psicologia da anorexia nervosa. Sao Paulo, SP: Summus, 1992. 127p. ISBN 853230124X

THIN ideal starts very young. Flinders Journal. March 14 - March 27, 2005. Adelaide, Australia: Flinders University. Disponível na Internet em: <http://www.flinders.edu.au/news/articles/ ?fj03v16s01>. Acesso em 18 mar 2005. 
TRINDADE, Antonio Augusto Cançado. A proteção internacional dos direitos humanos: fundamentos juridicos e instrumentos basicos. São Paulo: 1991. 742p 1v. ISBN 8502009133: (Enc.)

VIANNA, Cynthia Semíramis. Emagrecer é preciso?. Disponível na Internet em: <http://direitoinformatico.org/cynthia/?p=157>. Acesso em 24 nov 2004.

WOLF, Naomi. O mito da beleza: como as imagens de beleza são usadas contra as mulheres. Rio de Janeiro: Rocco, 1992. 439 p ISBN 8532501311

WORLD Health Organization. Obesity and overweight. Disponível na Internet em:

<http://www.who.int/entity/dietphysicalactivity/media/en/gsfs_obesity.pdf >. Acesso em 01 mar 2005. 